\title{
Pretreatment with a grape seed proanthocyanidin extract downregulates proinflammatory cytokine expression in airway epithelial cells infected with respiratory syncytial virus
}

\author{
SU JIN KIM ${ }^{1}$, JIN-WOO LEE ${ }^{2,3}$, YOUNG-GYU EUN ${ }^{4}$, KUN HEE LEE ${ }^{4}$, \\ SEUNG GUN YEO ${ }^{4}$ and SUNG WAN KIM ${ }^{4}$ \\ ${ }^{1}$ Department of Otorhinolaryngology, Eulji University Hospital, Eulji University School of Medicine, Daejeon 35233; \\ ${ }^{2}$ College of Life Sciences \& Biotechnology, Korea University, Seoul 02841; ${ }^{3}$ Medical Science Research Institute, \\ Kyung Hee University Medical Center; ${ }^{4}$ Department of Otorhinolaryngology-Head and Neck Surgery, \\ Kyung Hee University School of Medicine, Seoul 02447, Republic of Korea
}

Received May 30, 2018; Accepted January 29, 2019

DOI: $10.3892 / \mathrm{mmr} .2019 .9967$

\begin{abstract}
Respiratory syncytial virus (RSV) infections are associated with significant morbidity and mortality. Inflammation is mediated by cytokine secretion from RSV-infected airway epithelial cells. Grape seed proanthocyanidin extract (GSPE) exhibits potent antioxidant capacity, as well as anti-bacterial, anti-viral, anti-carcinogenic, anti-inflammatory and anti-allergic actions. However, few studies have explored the anti-inflammatory effects of GSPE on airway epithelial cells infected with RSV. Airway epithelial A549 cells were pretreated with GSPE and its effects on cytokine production during RSV infection were investigated. A549 cells were infected with RSV, with or without GSPE pretreatment, and cultured for 24, 48 and $72 \mathrm{~h}$. The expression of interleukin (IL)-1 $\beta$, IL-6 and IL-8, were measured by reverse transcription-quantitative polymerase chain reaction, ELISA and western blotting. RSV infection induced significant increases in proinflammatory cytokine expression. However, GSPE pretreatment decreased the mRNA and protein expression levels of IL-1ß, IL-6 and IL-8. GSPE regulated the immune response by reducing the RSV-induced transcription of proinflammatory cytokines in airway epithelial cells, suggesting that GSPE helps to prevent RSV-induced airway disease.
\end{abstract}

\section{Introduction}

Respiratory syncytial virus (RSV) is a globally prevalent respiratory tract pathogen responsible for annual epidemics

Correspondence to: Professor Sung Wan Kim, Department of Otorhinolaryngology-Head and Neck Surgery, Kyung Hee Univerisity School of Medicine, 23 Kyungheedae-ro, Seoul 02447, Republic of Korea

E-mail: drkimsw@hanmail.net

Key words: proanthocyanidins, cytokines, inflammation, A549 cells, respiratory syncytial virus infection of respiratory disease. RSV infections place a heavy burden on healthcare systems and are associated with significant morbidity and mortality (1). Although the exact mechanism of RSV-induced airway disease remains unclear, the inflammatory response is thought to have a central pathogenic role (2). Reactive oxygen species may serve as important regulators of RSV-induced inflammatory responses (2). Acute RSV infection induces intense neutrophilia within the airway epithelium (3), predominantly driven by high levels of interleukin (IL)-8, a chemoattractant and activator of neutrophils $(4,5)$. Prolonged neutrophil survival contributes to mucosal inflammation, in turn triggering a symptomatic respiratory tract infection. The clinical manifestations range from mild upper respiratory tract illness to severe and potentially life-threatening lower respiratory tract disease (6). Although the epidemiology, clinical manifestations, diagnostic techniques and immunobiology of the disease have been well studied, and animal models established, no safe vaccine is currently available (6).

Grape seed proanthocyanidin extract (GSPE) is composed of biologically active polyphenolic flavonoids, including oligomeric proanthocyanidins. The latter compounds are naturally found in vegetables, fruit, nuts, seeds, and bark (7). Grape seeds are a particularly rich source of proanthocyanidins, in terms of both quantity and variety (7). GSPE is the key cardioprotective element of red wine (8). It has a greater antioxidant capacity than vitamin $\mathrm{C}$ or $\mathrm{E}$ (7), and is sold as a dietary supplement because of this activity, which is associated with low toxicity and genotoxicity. Anticancer effects of GSPE, attributable to the free radical-scavenging ability, have also been reported $(9,10)$. Some studies found that GSPE exhibited anti-inflammatory properties (11); however, few studies have explored the anti-inflammatory effects of GSPE on RSV-infected airway epithelial cells.

Therefore, the present study investigated the alterations in proinflammatory cytokine production in RSV-infected airway epithelial A549 cells, in the presence or absence of GSPE pretreatment. The aim of the study was to evaluate the potential of utilizing GSPE for prevention of RSV-induced airway disease. 


\section{Materials and methods}

Experimental design. A549 cells were subjected to GSPE pretreatment and infected with RSV. The experimental group underwent GSPE pretreatment and was infected with RSV; the negative (infected) control was not GSPE-pretreated. Another cell group received GSPE pretreatment, but was not infected. Uninfected cells with no pretreatment served as the reference. Fold changes in gene expression were calculated, relative to the reference group. Samples were taken after 24, 48 and $72 \mathrm{~h}$ of culture. All experiments were repeated three times. The experimental design is presented in Fig. 1.

Materials. GSPE from Vitis vinifera was supplied by Hanlim Pharmaceutical Co., Ltd. (CAS no. 71328-22-8; Seoul, Korea). GSPE contains proanthocyanidins ( $80 \%$ of all solids) and some catechin monomers (12). GSPE was solubilized in PBS. All chemicals were of analytical grade and were purchased from Sigma-Aldrich (Merck KGaA, Darmstadt, Germany) unless otherwise indicated. Dulbecco's modified Eagle's medium (DMEM), penicillin-streptomycin and trypsin-EDTA were purchased from Gibco (Thermo Fisher Scientific, Inc., Waltham, MA, USA). RPMI-1640 was purchased from Corning Inc. (Corning, NY, USA) and fetal bovine serum (FBS) was obtained from GE Healthcare (Chicago, IL, USA). R\&D Systems, Inc. (Minneapolis, MN, USA) supplied the ELISA kits used to measure IL-1 $\beta$, IL- 6 and IL- 8 expression. A primary antibody against IL-1 $\beta$ (Santa Cruz Biotechnology, Inc., Santa Cruz, CA, USA) and an appropriate secondary antibody (Cell Signaling Technology, Inc., Beverly, MA, USA) were used for western blotting.

Cell culture. The A549 human lung adenocarcinoma epithelial cell line and HeLa derivative HEp-2 cells were purchased from the Korean Cell Line Bank (Korean Cell Line Research Foundation, Seoul, South Korea). A549 cells were cultured in RPMI-1640 medium supplemented with $10 \%$ (v/v) FBS, $100 \mathrm{U} / \mathrm{ml}$ penicillin, $100 \mu \mathrm{g} / \mathrm{ml}$ streptomycin and $2 \mathrm{mM}$ glutamine. Cells were maintained in a $37^{\circ} \mathrm{C}$ humidified incubator under $5 \% \mathrm{CO}_{2}$ and $95 \%$ air (both v/v) until the desired confluency $(80 \%)$ was attained.

$R S V$ propagation and titer determination. RSV strain A2 was obtained from the American Type Culture Collection (Manassas, VA, USA). The virus was grown in HEp-2 cell monolayers with DMEM and 10\% (v/v) FBS, and purified as previously described $(13,14)$. Viral titer and growth were determined by quantitative plaque assays (15).

Infection of epithelial cells. A549 cells at $\sim 80 \%$ confluence were infected with RSV at a multiplicity of infection (MOI) of 3 for $60 \mathrm{~min}$ at $37^{\circ} \mathrm{C}$. Following adsorption, the viral solution was removed, cells were rinsed twice with PBS, and incubation was continued in RPMI-1640 medium supplemented with $10 \% \mathrm{FBS}, 100 \mathrm{U} / \mathrm{ml}$ penicillin, $100 \mu \mathrm{g} / \mathrm{ml}$ streptomycin and $2 \mathrm{mM}$ glutamine for $72 \mathrm{~h}$ at $37^{\circ} \mathrm{C}$. Samples were taken at 24, 48 and $72 \mathrm{~h}$ for RNA and protein extraction; the culture supernatants were stored at $-80^{\circ} \mathrm{C}$ prior to ELISAs. Cells infected with RSV served as negative controls and uninfected cells as the reference group.
Cell viability upon GSPE treatment. The potential effects of GSPE on A549 cell viability were determined. Cells were grown in 6 -well plates $\left(1 \times 10^{5}\right.$ per well) for $24 \mathrm{~h}$ at $37^{\circ} \mathrm{C}$, following which GSPE was added at the indicated concentrations $(5,10,20,30,40,50$ and $100 \mu \mathrm{g} / \mathrm{ml})$; the control group received $0.01 \%(\mathrm{v} / \mathrm{v}) \mathrm{PBS}$. After incubation at $37^{\circ} \mathrm{C}$ for 24 , 48 and $72 \mathrm{~h}$, cells were harvested with trypsin-EDTA solution (JBI, Seoul, South Korea), washed once in PBS with $5 \%$ (v/v) FBS, and counted using an ADAM-MC cell counter (NanoEnTek, Inc., Seoul, South Korea).

Reverse transcription-quantitative polymerase chain reaction $(R T-q P C R)$. The mRNA expression of IL-1 $\beta$, IL- 6 and IL- 8 was measured by RT-qPCR. Total cellular RNA was obtained with TRIzol reagent (Invitrogen; Thermo Fisher Scientific, Inc.). First-strand cDNA was synthesized by reverse transcription in a reaction mixture $(20 \mu \mathrm{l})$ containing $1 \mathrm{mM}$ of each $\mathrm{dNTP}, 1 \mu \mathrm{g}$ RNA, $1 \mathrm{X}$ reaction buffer, $5 \mu \mathrm{M}$ random primers and 20 units AMV reverse transcriptase (Promega Corporation, Madison, WI, USA). cDNA synthesis was performed at $25^{\circ} \mathrm{C}$ for $10 \mathrm{~min}$ for primer annealing, $42^{\circ} \mathrm{C}$ for $60 \mathrm{~min}$ for reverse transcription and $95^{\circ} \mathrm{C}$ for $5 \mathrm{~min}$ for transcriptase denaturation. The sequences of the gene-specific primers used were as follows: IL-1 $\beta$ forward, 5'-TGATGGCTTATTACAGTGGCAATG-3' and reverse, 5'-GTAGTGGTGGTCGGAGATTCG-3' (140 bp); IL-6 forward, 5'-GTCTTGCCTGCTGCCTTC-3' and reverse, 5'-AGTGCCTCTTTGCTGCTTTC-3' (194 bp); IL-8 forward, 5'-GACATACTCCAAACCTTTCCAC-3' and reverse, 5'-CTT CTCCACAAACCTCTGC-3' (160 bp); and $\beta$-actin forward, 5'-GCGAGAAGATGACCCAGATC-3' and reverse, 5'-GGA TAGCACAGCCTGGATAG-3' (77 bp). PCR was performed in a StepOnePlusÔ Real-Time PCR system (Applied Biosystems; Thermo Fisher Scientific, Inc.). Each reaction mixture $(20 \mu \mathrm{l})$ contained $1 \mu \mathrm{l} \mathrm{cDNA}, 1 \mu \mathrm{l}$ solutions of both the reverse and forward primers, $10 \mu \mathrm{l}$ Power SYBR-Green PCR Master Mix, and $7 \mu \mathrm{l} \mathrm{PCR}$-grade water. The amplification protocol included initial denaturation at $95^{\circ} \mathrm{C}$ for $10 \mathrm{~min}$, followed by 40 cycles of denaturation $\left(95^{\circ} \mathrm{C}\right.$ for $\left.15 \mathrm{sec}\right)$ and annealing $\left(60^{\circ} \mathrm{C}\right.$ for $1 \mathrm{~min}$ ). Relative gene expression was calculated using the $2^{-\Delta \Delta C q}$ method (16). The data were normalized to the control group and are presented as fold changes in mRNA expression (three experiments/group).

ELISA. A549 cells were seeded into 6-well plates at a density of $1.5 \times 10^{5}$ cells/well and incubated in RPMI-1640 with $2 \%(\mathrm{v} / \mathrm{v}) \mathrm{FBS}$ for $72 \mathrm{~h}$ at $37^{\circ} \mathrm{C}$ to avoid the confounding effect of serum-induced cytokine expression. Cells were cultured (with or without GSPE pretreatment) for $24 \mathrm{~h}$ prior to RSV infection (at a MOI of 3) for $1 \mathrm{~h}$ at $37^{\circ} \mathrm{C}$. After 24, 48 and $72 \mathrm{~h}$ of infection, the culture media were collected and centrifuged at 2,000 x g for $10 \mathrm{~min}$ at $4^{\circ} \mathrm{C}$ to remove cell debris. The supernatants were subjected to IL-1 $\beta$ (cat. no. DLB50), IL-6 (cat. no. D6050) and IL-8 (cat. no. D8000C) (all from R\&D Systems, Inc.) ELISAs, in accordance with the manufacturer's instructions.

Western blotting. Pretreated A549 cells were infected with RSV (at a MOI of 3) in serum-free RPMI-1640 for $60 \mathrm{~min}$ at $37^{\circ} \mathrm{C}$, and grown under optimal conditions for $72 \mathrm{~h}$ at $37^{\circ} \mathrm{C}$. Next, cells were washed with cold PBS and lysed with lysis 


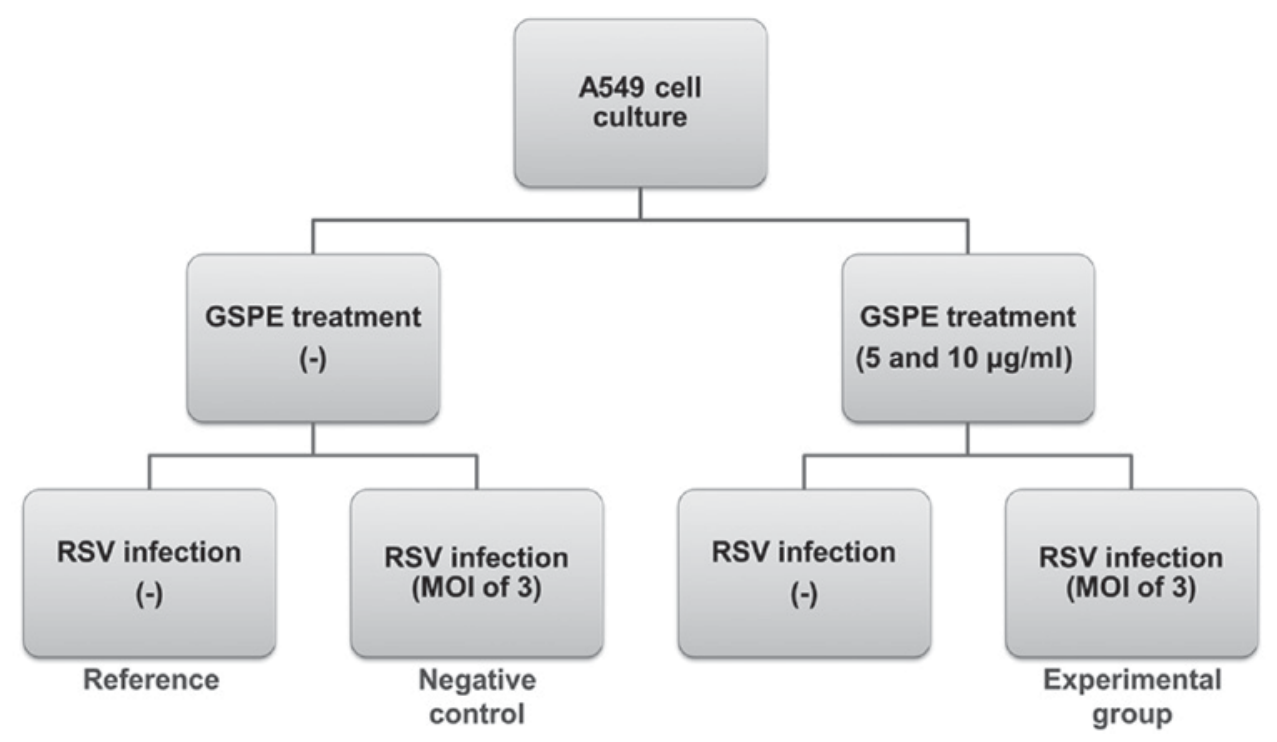

Figure 1. Schematic of the experimental design. GSPE, grape seed proanthocyanidin extract; RSV, respiratory syncytial virus; MOI, multiplicity of infection.

buffer (Cell Signaling Technology, Inc.). A bicinchoninic acid protein assay was used to determine total protein concentration. Protein $(30 \mu \mathrm{g})$ was mixed with loading buffer, boiled for 5 min and loaded onto $12 \%(\mathrm{w} / \mathrm{v})$ polyacrylamide gels. After electrophoresis, proteins were transferred onto polyvinylidene difluoride membranes. Membranes were blocked in 5\% (w/v) non-fat milk powder solution for $1 \mathrm{~h}$ at room temperature, and subsequently incubated overnight at $4^{\circ} \mathrm{C}$ in Tris-buffered saline with $0.05 \%(\mathrm{v} / \mathrm{v})$ Tween-20 (TBS-T) containing primary antibodies against IL-1 $\beta$ (1:250; cat. no. sc-7884; Santa Cruz Biotechnology, Inc.) and $\beta$-actin (1:1,000; cat. no. 4970S; Cell Signaling Technology, Inc.). Following washing with TBS-T, the membranes were soaked in TBS-T containing goat anti-rabbit IgG horseradish peroxidase-conjugated secondary antibodies (1:2,500; cat. no. 7074; Cell Signaling Technology, Inc.) for $1 \mathrm{~h}$ at room temperature. Following a further wash with TBS-T, target protein bands were visualized using an Enhanced Chemiluminescence kit (Thermo Fisher Scientific, Inc.) and a Davinch-Chemi ${ }^{\mathrm{TM}}$ Chemiluminescence Imaging system (Davinch-K Co., Ltd., Seoul, South Korea). Densitometric analysis of scanned immunoblot images was performed using Image J software version 1.49 (National Institutes of Health, Bethesda, MD, USA).

Statistical analysis. All values are expressed as the mean \pm standard deviation. SPSS version 23.0 (IBM Corp., Armonk, NY, USA) was used for statistical analyses. SigmaPlot version 10 (Systat Software, Inc., Chicago, IL, USA) was used for plotting graphs. Two-way analysis of variance followed by Bonferroni's post-hoc test was used to determine the statistical significance of differences between GSPE pretreatment groups and groups subjected to RSV infection alone. In all analyses, $\mathrm{P}<0.05$ was considered to indicate a statistically significant difference.

\section{Results}

GSPE treatment does not affect A549 cell viability at 5 or $10 \mu \mathrm{g} / \mathrm{ml}$. The optimal concentration for GSPE treatment was

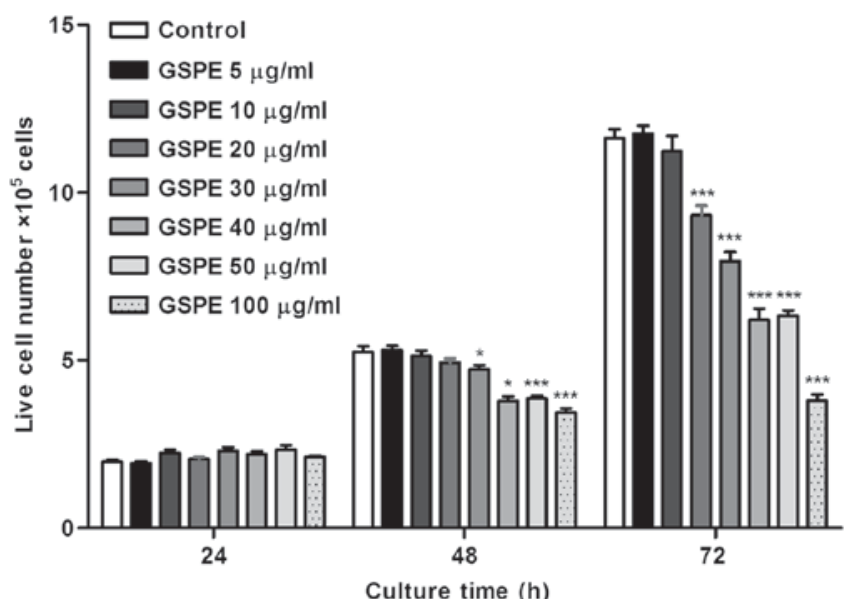

Figure 2. A549 cell viability following treatment with GSPE. Data are expressed as the mean \pm standard deviation from three independent experiments. One-way analysis of variance followed by Bonferroni's post-hoc test was used to determine the statistical significance of differences between the indicated concentrations $(5,10,20,30,40,50$, and $100 \mu \mathrm{g} / \mathrm{ml})$ of GSPE and the control values at each time-point. ${ }^{*} \mathrm{P}<0.05,{ }^{* * *} \mathrm{P}<0.01$ and ${ }^{* * *} \mathrm{P}<0.001$ vs. control. GSPE, grape seed proanthocyanidin extract.

evaluated by exposing A549 cells to varying concentrations $(5,10,20,30,40,50$ and $100 \mu \mathrm{g} / \mathrm{ml})$ of GSPE for 24,48 and $72 \mathrm{~h}$. The data are expressed as cell numbers compared with those in the control group (Fig. 2). It was determined that GSPE was not toxic at either 5 or $10 \mu \mathrm{g} / \mathrm{ml}$; therefore, these concentrations used in all subsequent experiments.

GSPE decreases proinflammatory cytokine gene expression. To evaluate the effects of GSPE pretreatment on RSV-infected A549 cells, the mRNA expression of IL- $1 \beta$, IL-6 and IL-8 was determined by RT-qPCR. RSV infection significantly increased the mRNA expression of IL-1 $\beta$, IL-6 and IL-8, compared with the control group. However, GPSE pretreatment significantly decreased the expression of IL-1 $\beta$ mRNA (from 24.23 - to 0.59 -fold at $5 \mu \mathrm{g} / \mathrm{ml}$, and to 0.20 -fold at $10 \mu \mathrm{g} / \mathrm{ml}$ after 48 h; Fig. 3A). In addition, the mRNA expression of IL-6 

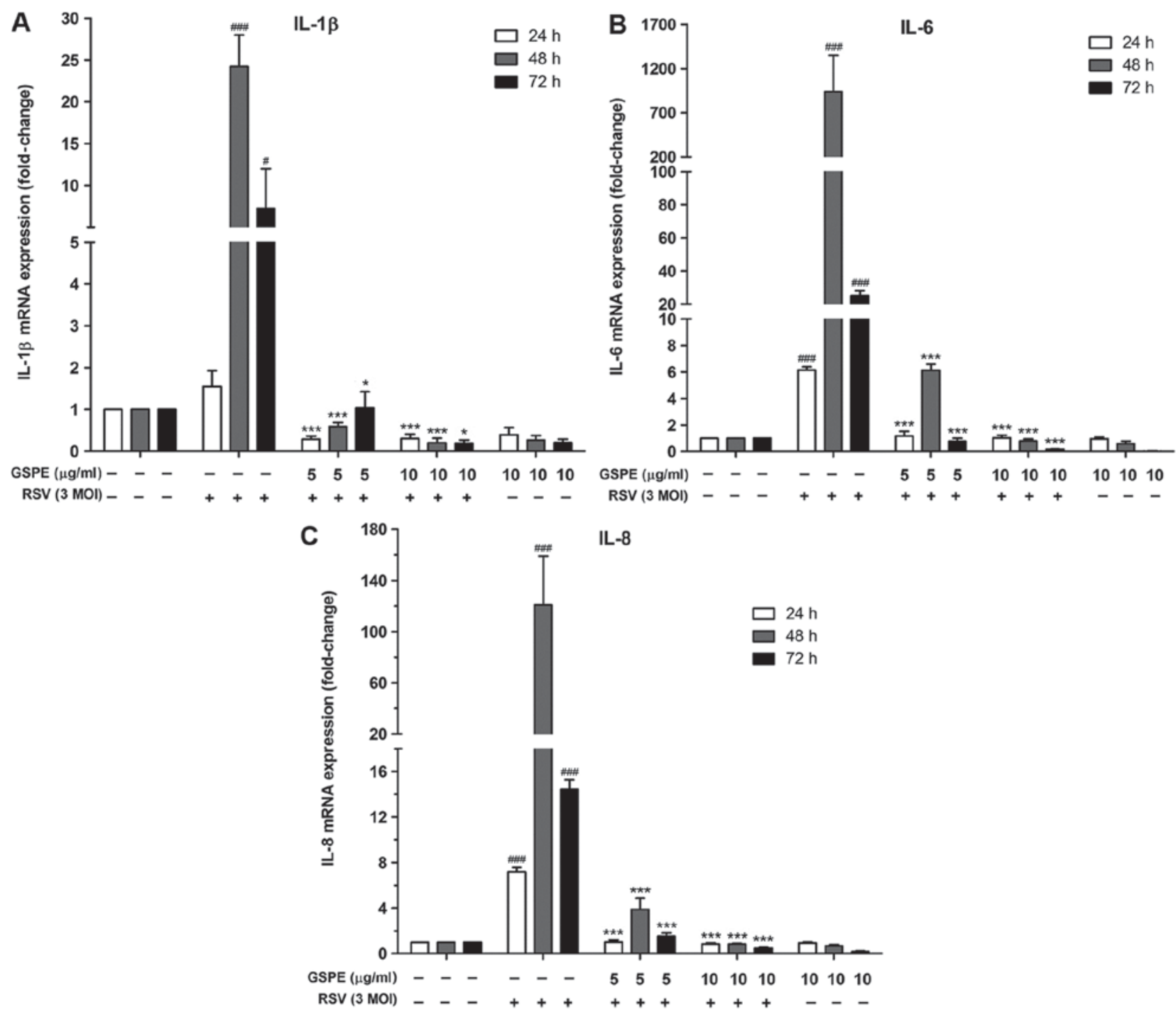

Figure 3. Proinflammatory cytokine expression in response to GSPE treatment was measured by reverse transcription-quantitative polymerase chain reaction. Effects of GSPE pretreatment on the expression of mRNAs encoding (A) IL-1 $\beta$, (B) IL-6 and (C) IL-8 in A549 cells infected with RSV. Each bar represents the mean \pm standard deviation of data from three independent experiments. Two-way analysis of variance followed by Bonferroni's post-hoc test was used to compare values. ${ }^{*} \mathrm{P}<0.05$ and ${ }^{\# \# \#} \mathrm{P}<0.001$ vs. control; ${ }^{*} \mathrm{P}<0.05$ and ${ }^{* * * *} \mathrm{P}<0.001$ vs. RSV infection alone. IL, interleukin; GSPE, grape seed proanthocyanidin extract; RSV, respiratory syncytial virus; MOI, multiplicity of infection.

significantly decreased (from 939.04- to 6.13 -fold at $5 \mu \mathrm{g} / \mathrm{ml}$, and to 0.80 -fold at $10 \mu \mathrm{g} / \mathrm{ml}$ after $48 \mathrm{~h}$; Fig. 3B). Similarly, the expression of IL-8 mRNA decreased (from 120.85- to 3.87-fold at $5 \mu \mathrm{g} / \mathrm{ml}$, and to 0.84 -fold at $10 \mu \mathrm{g} / \mathrm{ml}$; Fig. 3C). All changes were significant compared with the RSV infection-alone group.

GSPE decreased proinflammatory cytokine protein expression. ELISAs were performed to confirm the effects of GSPE on proinflammatory cytokine protein expression. However, the ELISA did not detect IL-1 $\beta$ protein expression; thus additional western blot analysis was performed, using a polyclonal antibody against IL-1 $\beta$. Negligible IL-1 $\beta$ expression was detected at baseline, but expression increased upon RSV infection (at an MOI of 3). GSPE pretreatment (5 or $10 \mu \mathrm{g} / \mathrm{ml}$ ) significantly reduced IL-1 $\beta$ expression (Fig. 4). The levels of IL-6 (Fig. 5A) and IL-8 (Fig. 5B), as determined by ELISAs, significantly increased upon RSV infection (at an MOI of 3) compared with the control, whereas GSPE pretreatment significantly reduced the production of these factors.

\section{Discussion}

The present study examined whether GSPE suppressed RSV-induced inflammation in the human respiratory epithelial cell line A549. To the best of our knowledge, this is the first study to have investigated the potential preventative effects of GSPE in the context of RSV-induced airway disease. It was demonstrated that GSPE pretreatment suppressed RSV-induced proinflammatory cytokine production, specifically that of IL-1 $\beta$, IL-6 and IL-8, in RSV-infected A549 cells. This suggested that GSPE may be a valuable preventative agent when used to treat airway inflammation caused by RSV infection.

Although the mechanisms of RSV-induced airway disease remain incompletely understood, inflammatory responses likely serve fundamental roles in its pathogenesis (2). A bronchoalveolar lavage (BAL) study reported that neutrophils were the most abundant cell type identified in patients with RSV infections, constituting up to $85 \%$ of all cells (17). 

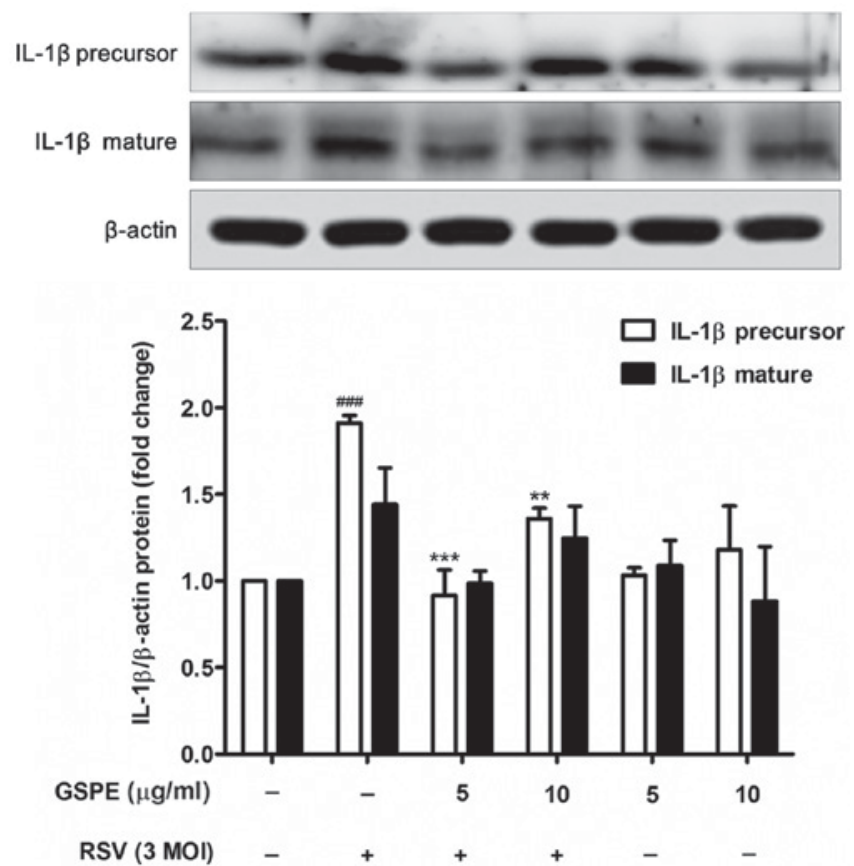

Figure 4. Effect of GSPE pretreatment on the protein expression of IL-1 $\beta$ in A549 cells infected with RSV. Precursor $(31 \mathrm{kDa})$ and mature $(17 \mathrm{kDa})$ IL-1 $\beta$ expression was examined by western blotting. Each bar represents the mean \pm standard deviation of data from three independent experiments. Two-way analysis of variance followed by Bonferroni's post-hoc test was used to compare the values. ${ }^{\# \# \#} \mathrm{P}<0.001$ vs. control, ${ }^{* * *} \mathrm{P}<0.01$ and ${ }^{* * * *} \mathrm{P}<0.001$ vs. RSV infection alone. IL, interleukin; GSPE, grape seed proanthocyanidin extract; RSV, respiratory syncytial virus; MOI, multiplicity of infection.

Inflammation dominated by intense neutrophilia in the upper and lower airways is the principal mechanism of RSV infection (18). Neutrophil products including myeloperoxidase and neutrophil elastase make significant contributions to mucosal inflammation, increasing airway secretion, coughing, and sneezing (4). Therefore, neutrophils may be critically involved in symptom causation; they also likely contribute to viral transmission by increasing mucus levels, thus enhancing the production of infected respiratory droplets (19).

Neutrophilia is driven by cytokines such as IL-6 and IL-8, that are produced in response to RSV; these cytokines stimulate airway neutrophil generation and recruitment (18). Previous studies have demonstrated that the RSV F protein activates innate immunity via Toll-like receptor 4 and CD14 ${ }^{+}$ monocytes, stimulating the production of proinflammatory cytokines (such as IL-1 $\beta$, IL-6 and IL-8) by promoting nuclear translocation of the transcription factor NF- $\mathrm{kB}(20,21)$. Reactive oxygen species may serve as important regulators of RSV-induced cellular signaling, which in turn triggers the expression of proinflammatory cytokines (2). These proinflammatory cytokines have critical function in neutrophil and macrophage chemotaxis and activation during RSV infection (21). Neutrophil numbers positively correlate with IL-8 expression, and both of these factors are associated with symptom severity (22). Therefore, inhibition of proinflammatory cytokine synthesis prior to symptomatic RSV infection is an important strategy for preventing mucosal inflammation.

GSPE is a known antioxidant exerting beneficial effects in patients with oxidative stress-associated diseases (7). Along with the many other beneficial effects of GSPE, its
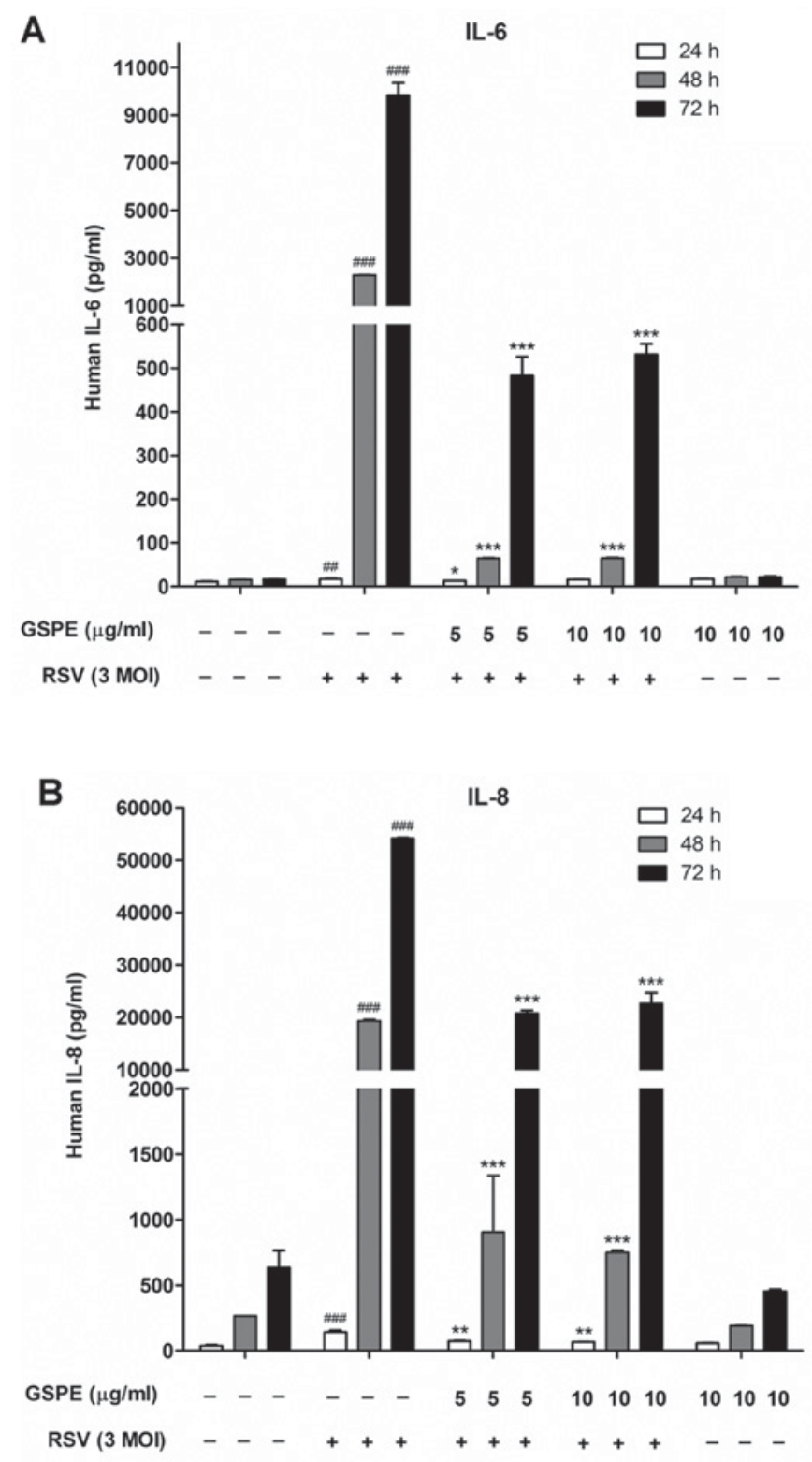

Figure 5. Effect of GSPE pretreatment on the expression of IL-6 and IL-8 in A549 cells infected with RSV. (A) IL-6 and (B) IL-8 expression was detected by ELISAs. Each bar represents the mean \pm standard deviation of data from three independent experiments. Two-way analysis of variance followed by Bonferroni's post-hoc test was used to compare values. ${ }^{\# \prime} \mathrm{P}<0.01$ and ${ }^{\# \# \#} \mathrm{P}<0.001$ vs. control; ${ }^{*} \mathrm{P}<0.05,{ }^{* *} \mathrm{P}<0.01$ and ${ }^{* * * *} \mathrm{P}<0.001$ vs. RSV infection alone. IL, interleukin; GSPE, grape seed proanthocyanidin extract; RSV, respiratory syncytial virus; MOI, multiplicity of infection.

anti-inflammatory effect has been studied (11,23-25). A previous in vitro study showed that GSPE inhibits the production of nitric oxide and prostaglandin $\mathrm{E}_{2}$, and suppresses inducible nitric oxide synthase and NF- $\kappa \mathrm{B}$ expression, thereby exerting anti-inflammatory effects (23). Others have reported that GSPE may be beneficial when used to treat low-grade inflammatory diseases; such effects may be associated with inhibition of proinflammatory cytokines and stimulation of anti-inflammatory adiponectin production $(11,24)$. GSPE attenuates not only the production of inflammation-associated adipokines, but also that of reactive oxygen species in experiments involving the coculture of adipocytes and macrophages; implying that GSPE has anti-inflammatory effects via its 
antioxidant properties (26). Although not GSPE, the administration of antioxidants to RSV-infected mice revealed that antioxidant treatment reduced RSV-induced oxidative stress, RSV-induced lung inflammation, airway hyper-reactivity and clinical illness (27). Based on such findings, it was hypothesize that GSPE may protect against airway epithelial cell inflammation following RSV infection.

In the present study, GSPE pretreatment of airway epithelial cells infected with RSV evidently resulted in the suppression of proinflammatory cytokine expression, including IL-1 $\beta$, IL-6 and IL-8. Notably, IL-1 $\beta$ was detected by western blot analysis, but not ELISA. This could be due to the low levels of secreted IL-1 $\beta$, which was not sufficient to be measured by ELISA. Inflammatory stimuli, such as RSV infection, induce excessive cytokine production, which enhances the immune response and subsequent inflammation (6). Therefore, anti-inflammatory therapies often target proinflammatory cytokines (28). It is therefore of note that GSPE exerted its anti-inflammatory effects by inhibiting synthesis of the IL-1 $\beta$, IL-6 and IL-8 protein. The antioxidant action of GSPE may also serve an anti-inflammatory role by eliminating reactive oxygen species; these significantly affect the pathogenesis of RSV infection (2). GSPE may reduce RSV-induced oxidative stress and inhibit the production of inflammatory mediators such as cytokines and chemokines, and, consequentially reduce RSV-induced lung inflammation (27). This suggests that GSPE may be useful to prevent and treat RSV-induced airway disease.

In the present study, cells were pretreated with GSPE at 5 and $10 \mu \mathrm{g} / \mathrm{ml}$. In preliminary experiments, cells were exposed to GPSE at concentrations between 5-100 $\mu \mathrm{g} / \mathrm{ml}$. GSPE at $\geq 20 \mu \mathrm{g} / \mathrm{ml}$ was associated with significant cytotoxicity. Thus, GSPE at 5 and $10 \mu \mathrm{g} / \mathrm{ml}$ was selected. Earlier investigators performed toxicity studies to evaluate the safety of GSPE, which demonstrated that GSPE was safe at higher concentrations in vivo and in vitro (7).

The present study had several limitations. This was a preliminary work that evaluated the anti-inflammatory effects of GSPE in RSV-induced airway disease. A549 human lung adenocarcinoma epithelial cells were used, which are not physiologically representative of the human airway epithelium. The expression of only three proinflammatory cytokines was examined and the underlying signaling pathways were not investigated. In addition, the levels of reactive oxygen species were not evaluated. These limitations will be addressed in future research.

In conclusion, GSPE pretreatment may have regulated the immune response by reducing RSV infection-induced transcription of proinflammatory cytokines in airway epithelial cells. GSPE pretreatment significantly suppressed IL-1 $\beta$, IL-6 and IL- 8 expression, suggesting that GSPE may serve as a preventative agent in RSV-induced airway disease.

\section{Acknowledgements}

Not applicable.

\section{Funding}

No funding was received.

\section{Availability of data and materials}

The datasets used and/or analyzed during the current study are available from the corresponding author on reasonable request.

\section{Authors' contributions}

SWK designed the study. SJK and JWL performed the experiments, and analyzed and interpreted the data. SJK wrote the manuscript. YGE, KHL, SGY and SWK were involved in the interpretation of data and revised the manuscript for important intellectual content. All authors have read and approved of the final manuscript.

\section{Ethics approval and consent to participate}

Not applicable.

\section{Patient consent for publication}

Not applicable.

\section{Competing interests}

The authors declare that they have no competing interests.

\section{References}

1. Bont L, Checchia PA, Fauroux B, Figueras-Aloy J, Manzoni P, Paes B, Simões EA and Carbonell-Estrany X: Defining the epidemiology and burden of severe respiratory syncytial virus infection among infants and children in Western countries. Infect Dis Ther 5: 271-298, 2016.

2. Garofalo RP, Kolli D and Casola A: Respiratory syncytial virus infection: Mechanisms of redox control and novel therapeutic opportunities. Antioxid Redox Signal 18: 186-217, 2013.

3. Smith PK, Wang SZ, Dowling KD and Forsyth KD: Leucocyte populations in respiratory syncytial virus-induced bronchiolitis. J Paediatr Child Health 37: 146-151, 2001.

4. Abu-Harb M, Bell F, Finn A, Rao WH, Nixon L, Shale D and Everard ML: IL-8 and neutrophil elastase levels in the respiratory tract of infants with RSV bronchiolitis. Eur Respir J 14: 139-143, 1999.

5. Jones A, Qui JM, Bataki E, Elphick H, Ritson S, Evans GS and Everard ML: Neutrophil survival is prolonged in the airways of healthy infants and infants with RSV bronchiolitis. Eur Respir J 20: 651-657, 2002.

6. Borchers AT, Chang C, Gershwin ME and Gershwin LJ: Respiratory syncytial virus-a comprehensive review. Clin Rev Allergy Immunol 45: 331-379, 2013.

7. Bagchi D, Bagchi M, Stohs SJ, Das DK, Ray SD, Kuszynski CA, Joshi SS and Pruess HG: Free radicals and grape seed proanthocyanidin extract: Importance in human health and disease prevention. Toxicology 148: 187-197, 2000.

8. Bagchi D, Sen CK, Ray SD, Das DK, Bagchi M, Preuss HG and Vinson JA: Molecular mechanisms of cardioprotection by a novel grape seed proanthocyanidin extract. Mutat Res 523: 87-97, 2003.

9. Akhtar S, Meeran SM, Katiyar N and Katiyar SK: Grape seed proanthocyanidins inhibit the growth of human non-small cell lung cancer xenografts by targeting insulin-like growth factor binding protein-3, tumor cell proliferation, and angiogenic factors. Clin Cancer Res 15: 821-831, 2009.

10. Bagchi D, Swaroop A, Preuss HG and Bagchi M: Free radical scavenging, antioxidant and cancer chemoprevention by grape seed proanthocyanidin: An overview. Mutat Res 768: 69-73, 2014.

11. Chacón MR, Ceperuelo-Mallafré V, Maymó-Masip E, Mateo-Sanz JM, Arola L, Guitiérrez C, Fernandez-Real JM, Ardèvol A, Simón I and Vendrell J: Grape-seed procyanidins modulate inflammation on human differentiated adipocytes in vitro. Cytokine 47: 137-142, 2009. 
12. Gabetta B, Fuzzati N, Griffini A, Lolla E, Pace R, Ruffilli T and Peterlongo F: Characterization of proanthocyanidins from grape seeds. Fitoterapia 71: 162-175, 2000

13. Dakhama A, Park JW, Taube C, Joetham A, Balhorn A, Miyahara N, Takeda K and Gelfand EW: The enhancement or prevention of airway hyperresponsiveness during reinfection with respiratory syncytial virus is critically dependent on the age at first infection and IL-13 production. J Immunol 175: 1876-1883, 2005.

14. LeVine AM, Elliott J, Whitsett JA, Srikiatkhachorn A, Crouch E, DeSilva N and Korfhagen T: Surfactant protein-d enhances phagocytosis and pulmonary clearance of respiratory syncytial virus. Am J Respir Cell Mol Biol 31: 193-199, 2004.

15. McKimm-Breschkin JL: A simplified plaque assay for respiratory syncytial virus-direct visualization of plaques without immunostaining. J Virol Methods 120: 113-117, 2004.

16. Livak KJ and Schmittgen TD: Analysis of relative gene expression data using real-time quantitative PCR and the 2(-Delta Delta C(T)) method. Methods 25: 402-408, 2001.

17. Heidema J, Lukens MV, van Maren WW, van Dijk ME, Otten HG, van Vught AJ, van der Werff DB, van Gestel SJ, Semple MG, Smyth RL, et al: $\mathrm{CD}^{+} \mathrm{T}$ cell responses in bronchoalveolar lavage fluid and peripheral blood mononuclear cells of infants with severe primary respiratory syncytial virus infections. J Immunol 179: 8410-8417, 2007.

18. Russell CD, Unger SA, Walton M and Schwarze J: The human immune response to respiratory syncytial virus infection. Clin Microbiol Rev 30: 481-502, 2017.

19. Ugonna K, Douros K, Bingle CD and Everard ML: Cytokine responses in primary and secondary respiratory syncytial virus infections. Pediatr Res 79: 946-950, 2016.

20. Kurt-Jones EA, Popova L, Kwinn L, Haynes LM, Jones LP, Tripp RA, Walsh EE, Freeman MW, Golenbock DT, Anderson LJ and Finberg RW: Pattern recognition receptors TLR4 and CD14 mediate response to respiratory syncytial virus. Nat Immunol 1: 398-401, 2000.

21. Polack FP, Irusta PM, Hoffman SJ, Schiatti MP, Melendi GA, Delgado MF, Laham FR, Thumar B, Hendry RM, Melero JA, et al: The cysteine-rich region of respiratory syncytial virus attachment protein inhibits innate immunity elicited by the virus and endotoxin. Proc Natl Acad Sci USA 102: 8996-9001, 2005.
22. Henriquez KM, Hayney MS, Xie Y, Zhang Z and Barrett B: Association of interleukin- 8 and neutrophils with nasal symptom severity during acute respiratory infection. J Med Virol 87: 330-337, 2015.

23. Terra X, Valls J, Vitrac X, Mérrillon JM, Arola L, Ardèvol A, Bladé C, Fernandez-Larrea J, Pujadas G, Salvadó J and Blay M: Grape-seed procyanidins act as antiinflammatory agents in endotoxin-stimulated RAW 264.7 macrophages by inhibiting NFkB signaling pathway. J Agric Food Chem 55: 4357-4365, 2007.

24. Terra X, Montagut G, Bustos M, Llopiz N, Ardèvol A, Bladé C, Fernández-Larrea J, Pujadas G, Salvadó J, Arola L and Blay M: Grape-seed procyanidins prevent low-grade inflammation by modulating cytokine expression in rats fed a high-fat diet. J Nutr Biochem 20: 210-218, 2009.

25. Kim H, Kim JY, Song HS, Park KU, Mun KC and Ha E: Grape seed proanthocyanidin extract inhibits interleukin-17-induced interleukin-6 production via MAPK pathway in human pulmonary epithelial cells. Naunyn Schmiedebergs Arch Pharmacol 383: 555-562, 2011.

26. Sakurai T, Kitadate K, Nishioka H, Fujii H, Kizaki T, Kondoh Y, Izawa T, Ishida $\mathrm{H}$, Radák $\mathrm{Z}$ and Ohno H: Oligomerized grape seed polyphenols attenuate inflammatory changes due to antioxidative properties in coculture of adipocytes and macrophages. J Nutr Biochem 21: 47-54, 2010.

27. Castro SM, Guerrero-Plata A, Suarez-Real G, Adegboyega PA, Colasurdo GN, Khan AM, Garofalo RP and Casola A: Antioxidant treatment ameliorates respiratory syncytial virus-induced disease and lung inflammation. Am J Respir Crit Care Med 174: 1361-1369, 2006.

28. Bellik Y, Boukraâ L, Alzahrani HA, Bakhotmah BA, Abdellah F, Hammoudi SM and Iguer-Ouada M: Molecular mechanism underlying anti-inflammatory and anti-allergic activities of phytochemicals: An update. Molecules 18: 322-353, 2012. 